\begin{tabular}{c} 
Volume and Issues Obtainable at Center for Sustainability Research and Consultancy \\
Journal of Business and Social Review in Emerging Economies \\
ISSN: 2519-089X (E): 2519-0326 \\
Volume 7: No. 1, March 2021 \\
CSRᄃ \\
Journal homepage: www.publishing.globalcsrc.org/jbsee \\
\hline
\end{tabular}

\title{
Translating the Impacts of Self-Efficacy on the Ethical Behavior of Sales Force: The Moderating Role of Gender
}

*Fazal ur Rehman, Department of Business, Management \& Economics, University of Lakki Marwat, Pakistan

Farwida Javed, COMSATS University, Attock Campus, Pakistan

Sadia Ejaz Shiekh, COMSATS University, Attock Campus, Pakistan

Muhammad Mujtaba Asad, Department of Education, Sukkur IBA University, Sukkur, Pakistan

*Corresponding author's email address: fazal_marwatpk@yahoo.com

\begin{tabular}{l}
\hline ARTICLEDETAILS \\
\hline History \\
Revised format: Feb 2021 \\
Available Online: Mar 2021 \\
\hline Keywords \\
Self-efficacy, Ethical \\
Behavior, Gender, Sales \\
Force.
\end{tabular}

JEL Classification

M11, M12

\section{ABSTRACT}

Purpose: This study intends to assess the influence of selfefficacy on the ethical behavior of sales force along with the moderating effects of gender in the telecom sector at Pakistan. Design/Methodology/Approach: This study has collected data through self-administered questionnaire from the sales representatives in the telecom sector at Khyber Pakhtunkhwa, Pakistan. The collected data was analyzed using descriptive statistic and stepwise regression.

Findings: The results have shown that self-efficacy has positive significant effects while gender has positive but insignificant effects on the ethical behavior of sales force in the telecom sector of Pakistan. In addition, gender has moderating effects on the relationship of self-efficacy and the ethical behavior.

Implications/Originality/Value: This study is addressing a need to examine the influence of self-efficacy on the ethical behavior of sales force in less developed and less educated areas of Pakistan, which is useful and helpful to explore understanding in the nature of defined variables in the eastern culture of Pakistan where male gender is more dominant.

(C) 2021 The authors, under a Creative Commons Attribution-

NonCommercial 4.0

Recommended citation: Rehman, F.U., Javed, F., Sheikh, S. E. \& Asad, M. M. (2021). Translating the impacts of Self-Efficacy on the Ethical Behavior of Sales Force: The Moderating Role of Gender. Journal of Business and Social Review in Emerging Economies, 7(1) 139-147.

\section{Introduction}

Every organization needs valuable employees to effectively accomplish its objectives, as the skills, competencies and behavior of the competent employees may positively influence the organizational outcomes. Self-efficacy is the important factor that can enhance the behavior and performance of employees in the modern competitive market. A study (Stajkovic \& Luthans, 1998) has defined that self-efficacy is the level of confidence about one's ability to mobilize 
motivation and a course of actions needed to successfully accomplish a task in the given context. It may be the perceptions and beliefs of one own aptitude and cognitive resources. Hence, employees who possess the beliefs that they have abilities and possessions to face stressful and challenging environment may feel lower stress in demanding situations. It may perform a significant role in the improvement of occupational stress. Hence, people who possess the aptitudes to handle traumatic and stimulating tasks in difficult situation may feel easy and do not lose their confidence. It may perform a significant role in the improvement of occupational stress. While, ethical behavior is linked with the morality of employees and the sense to distinguish what is right and what is not in different circumstances. Ethics are honorable or non- honorable behaviors which may depend upon the situations and moral values. Exactly, Ate (2012) has defined "that ethics are the principles or a set of principles that are used to evaluate the right and wrong in the justice and truth perspectives. These predefined principles may develop a culture and provides direction 'how to behave in particular situations' to the staff of an organization, particularly in sales firms". Due to the reasons, many organizations define a set of ethical rules and standard for their employees and everyone is bound to follow for the smoothing business operations, and to show acceptable behavior in working environment. Therefore, this study has interest to examine whether self-efficacy has any connection with the ethical behavior of sales force in the telecom sector (in the eastern culture) of Pakistan or not? Is gender has moderating affect on this relationship? For getting these objectives, we need a study to investigate the relationship of self-efficacy with the ethical behavior of sales force in the telecom sector along with the moderating role of gender.

\section{Literature Review Self-efficacy}

Self-efficacy is an optimistic approach and a belief of own capabilities rather than anticipated outcome (Maddux, 1995). A study (Tierney \& Farmer, 2002) has linked this conception with the creativity of individuals and presumed that self-efficacious individuals are more creative than others. It was supported that employees having higher levels of self-efficacy are more efficient in their work and show better performance (Luthans, Zhu \& Avolio, 2006). Lam, Chen and Schaubroeck, (2002) have anticipated that self-efficacious individuals often more engage in their work as compared to less self-efficacious employees. Bandura and Locke(2003)have suggested that such individuals are more successful in their lives. Further, Stajkovic and Luthans (1998) have assessed 114 studies and noted that self-efficacy has a strong positive relationship with an employee's performance in a working environment. However, Chemers, Watson and May (2000) have noted that self-efficacious individual posses effective skills of leadership. It is believed that self-efficacious individual make better use of sources in demanding situations and may able to handle problematic errands in well-organized ways. Such individuals are expected to get work done in an efficient way in manufacturing, education and military industries (Dinther, Dochy \& Segers, 2011). As self-efficacy may escalate the level of efforts which are expanding and strengthening the persistence (Locke, 2003). It is believed that self-efficacy may influence the choices of activities which can enhance the level of performance through extending the complexity in self-set goals.

\section{Self Enhancement}

Self-enhancement is the sub part of self-efficacy and the level of motivation where employees may feel better about self and maintaining their standards in the working environment (Sedikides $\&$ Strube, 1995). Such employees may favor positive views rather than negative (Sedikides \& Gregg, 2008). Self-enhancement might help to get positivity into self concepts which are useful for self-evaluation and to avoid negativity (Dauenbeimer, Stablberg, Spreemann \& Sedikides, 2002). However, literature has mentioned four important types of self-enhancement that are; selfevaluation, self-assessment, self-verification and self-improvement. Where, self-evaluation may focus on personal development to assess what has improved and what needs to be improved. In 
self-assessment, employees may want accurate and intent evaluation of self and will try to reduce any uncertainty in this regards (Sedikides \& Strube, 1997). In self-verification, employees may want to verify their existing notions in themselves. While, in a self-improvement type of self enhancement individuals may try to improve their performance, attitude and character.

\section{Self-Confidence}

The word confidence is derived from the Latin word "confider" which means to have full trust or to be sure, but when we smack a word "self" at the start of confidence to compose a word like "self-confidence" then it means "to have full trust in yourself". Hence, self-confidence is the belief about one's ability to handle problematic situations in an organization (Grob, 2015). Therefore, Leaders may get sagacity of self-confidence while observing their skills in getting work done in an organization. This may cause of learning and confidence to get work done to be succeeded and gives the courage to effectively communicate, behave and decide on special occasion (MacIntyre, Clément, Dörnyei \& Noels, 1998). Whereas, Jack (2013) has assumed that manager's confidence can be measured through the achievement of objectives and sustaining high level performance in an organization. However, organizations may often use manager knowledge, abilities, and the skills as a criterion for determining their level of confidence. The quality of willing to be a team member and trust in managers may also give an indication about their confidence. However, the literature has mentioned two sub types of self-confidence that are; general self-confidence which is the aggregation of your own evaluation in different situations, while specific self-confidence is referred to one's abilities and skills to handle a specific task (Grob, 2015).

\section{Ethical Behavior}

Ethics are acceptable behaviors, manners and values and "the set of principles to assess the right and wrong approach in different situations" (Ate, 2012). It has noted that ethical behavior measure the attitude of employees in business environment and it has direct or indirect influence on the operations of a business. According to Gangwani (2012), organizations often settle ethical measure to control unethical manners of employees in the day to day business operations. For instance, a common unethical behavior of employees in the working environment is to dial long run call on business line during business times, and scoring false records of working hours and participation in illegal issues. They may often use the duplication of software to leak data of a business. Therefore, the predefined and settled principles of ethics are used as barriers for unethical behavior, particularly in the sale field as they often show the face of business in a market. Sometime, unethical behaviors are used to measure or test the ethical behavior of employees in an organization. It often creates confusion for managers to decide, if a problem exists between the right and wrong prospective and not too clear to understand due to cultural and societiesdifferences. Therefore, managers use different approaches to understand what is right or acceptable in a particular society and what is not. For instance, if an employee makes a call to keep business line busy for several hours is perceived as unethical but the employee can defend it in some useful context. Therefore, it is often mandatory to define a clear set of rules, policies and ethics for the smooth business operations and management enforced it to avoid the appearance of unethical behavior inside the working environment. In some cases, the implementation of these rules is difficult due to unstructured working environment, shortage of time or capabilities of workers etc. Therefore, this present study has interest to examine the relationship of self-efficacy with the ethical behavior (in the less developed, less educated, and in the eastern culture of Pakistan) of sales force in the sector of telecommunication.

\section{Moderating Role of Gender}

It may be interesting to know about gender differences in regard of self-efficacy and its relationship with the ethical behavior (in the eastern part of Pakistan, where male gender is more dominant) among the employees of telecom sector. Literature has noted gender differences in 
various aspects in different organizations. For example, Gefen and Straub (1997) have noted a considerable difference between male and female respondents in the terms of email usage. Likewise, Venkatesh and Morris (2000) have noted a difference among male and female while using the software at the workplace. At the same time, Ono and Zavodny (2002) have noted thatmen have significant relationship with the usage of internet while females have nonsignificant. Nysveen, Pedersen and Thorbjornsen (2005) have conducted a study about mobile usage and observed a non-significant influence of gender in using mobile phone services. In addition, Ramayah and Osman (2005) have found that "male students spent more time to use the course website as compared to female students". Therefore, the authors of this study are interested to determine the moderating effects of gender on the self-efficacy and ethical behavior relationship.

\section{Theoretical Framework}

In current trend of academic research, many studies have shown significant interest in understanding the behavioral aspects of employees and their level of self-efficacy. For instance, Luthans and Youssef (2007) have shown their interest in the behavioral research. Boswell, Zimmerman, and Swider (2012) have examined the relationship of self-efficacy, job offer and intensity of the job searching behavior. At the same time, Saadellaoui and Gharbi (2012)have investigated self-efficacy in advertising of anti-tobacco context and its influence on the perceived ethicality of fear appeals among users. Likewise, Shacklock, Manning and Hort (2013) have investigated the effects of ethical climate, self-efficacy and the capacity to deliver ethical outcome in public sector human resource management. Later on, $\mathrm{Fu}(2013)$ has examined the impacts of emotional intelligence along with organizational commitment as well as job satisfaction on the ethical behavior of Chinese employees. Ren and Chadee (2017) have explored the relationship of ethical leadership and job satisfaction along with the moderating role of selfefficacy. Likewise, Sukserm and Takahashi (2012) have conducted a study to assess the relationship of learning with the ethical behavior along with the mediating role of self-efficacy. Therefore, several studies have been conducted in various aspects of self-efficacy as well as ethical behavior and its relationship with other variables, but previous literature had less focused on determining the relationship of self-efficacy with ethical behavior of sales force in the telecom sector of Pakistan. Therefore, this present study has noted a gap of knowledge to interpret the impacts of self-efficacy on the ethical behavior of sales force along with moderating role of gender, in the eastern culture of Pakistan where male gender is more dominant. The study has selected the telecom sector as sales force often deal with uneducated people in less developed areas of Pakistan. This study will examine the moderating effects of gender on the relationship of self-efficacy with ethical behavior due to non flexible culture of consumers. Therefore, to get accomplish this objective, this study has developed a theoretical framework of self-efficacy, ethical behavior and gender which is given in Figure 1. It describes that self-efficacy is independent variable, ethical behavior is dependent and gender is the moderator variable of the study. The following shown research framework was constructed to examine the relationship among defined variables. 


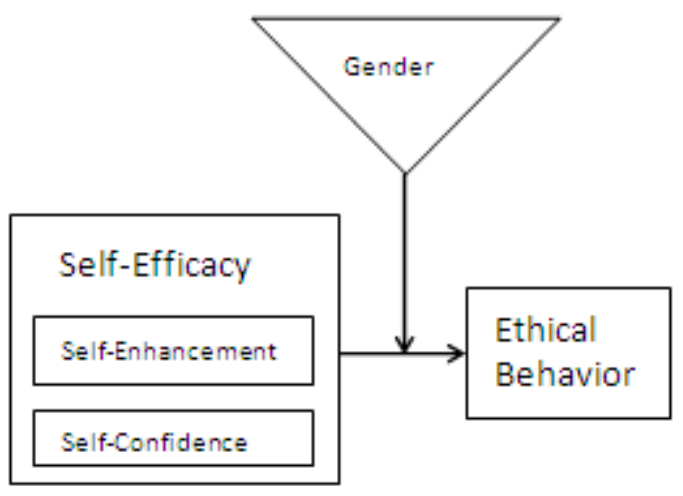

Figure 1: Theoretical Framework

On the basis of theoretical model, the study has formulated the following hypothesis; of

H1. Self-efficacy has significant effects on the ethical behavior of sales force in the telecom sector Pakistan.

H2. Genderhas significant effects on the ethical behavior of sales force in the telecom sector of Pakistan.

H3. Gender has moderating effects on the relationship of self-efficacy and the ethical behavior of the

Sales force in the telecom sector of Pakistan.

\section{Methodology}

This study has applied positivist approach to collect data through self-administered questionnaire based survey from the sales representatives in different regions of Khyber Pakhtunkhwa, Pakistan. This study has selected a sample of 302 sales representatives based on Morgan table but only 254 participants provided data. Majority of the participants were under the age of 35 years. The survey questionnaire was designed to collect the information's about demographic characteristics of respondents and other important variables. It was cleared to the participants that the provided information's only be used for publication purposes. However, the questionnaire was adopted from (Pelletier and Bligh, 2006; Yun, Takeuchi and Liu, 2007) to collect the information's about main variables. The study carried out a pilot study to ensure the accuracy and reliability of data instrument. For the purpose, 50 sales representatives provided data which was analyzed using SPSS to find results. The results of pilot study are presented in the below table.

Table 1: Values of Cronbach Alpha of Pilot Study

\begin{tabular}{c|c|c|c}
\hline S.No & Variables & Number of Items & Cronbach Alpha \\
\hline 1 & Self-Efficacy & 14 & 0.79 \\
\hline 2 & Ethical Behavior & 10 & 0.83 \\
\hline
\end{tabular}


After data collection, stepwise regression analysis was applied to find results and quantify the effects of self-efficacy, gender on the ethical behavior of sales fore in the telecom sector of Pakistan.

\section{Results}

This study has followed the procedure of correlation statistics to clarify the magnitude of correlation between the main variables of the study. The results are plainly highlighted in the below table.

Table 2: Correlation between Variables

\begin{tabular}{l|c|c}
\hline & Self-Efficacy & Ethical Behavior \\
\hline Self-Efficacy & 1 & \\
\hline Ethical Behavior & .536 & 1 \\
\hline$* *$ Correlation is significant at the 0.01 level \\
( 2- tailed)
\end{tabular}

The above table has presented the statistical results of correlation among the variables. Results indicate that self-efficacy $(\mathrm{r}=0.536)$ has positive correlation with the dependent variable in the eastern culture of Pakistan. In addition, the results of stepwise regression are presented in the below table. In the first step, self-efficacy has positive significant association $(\beta=0.47)$ with the ethical behavior in the defined context. Hence, it can be said that self-efficacy has positive linkage with the ethical behavior that can show favorable behavior to impress their targeted consumers. Moreover, self-efficacy, high level confidence and abilities of sales force may create good inspirations amongtargeted customers.

Table 3: Results of Hierarchical Regression Analysis

\begin{tabular}{l|c|c|c}
\hline & Beta Step.1 & Beta Step. II & Beta Step. III \\
\hline Self-efficacy & $.047 *$ & $.038^{*}$ & $.031^{*}$ \\
\hline Gender & & .231 & .418 \\
\hline Self-efficacy* Gender & & & $.041^{*}$ \\
\hline $\mathrm{R}^{2}$ & .527 & .614 & .543 \\
\hline Adjusted $\mathrm{R}^{2}$ & .326 & .336 & .368 \\
\hline$* * \mathrm{P}<0.01, * \mathrm{P}<0.05$ & & & \\
\hline
\end{tabular}

In step II, the effects of self-efficacy and gender were determined. In this step, self-efficacy $(\beta=$ $0.038)$ and gender $(\beta=0.231)$ both had a positive influence (in the eastern culture) in the telecom sector of Pakistan.

In this step, self-efficacy has significant while gender has an insignificant relationship with the ethical behavior of the sales force. In step III, a joint effect of self-efficacy and gender was determined by taking the product of gender and self-efficacy. In this step, self-efficacy $(\beta=$ 0.031) had positive significant relationship, while, gender $(\beta=0.418)$ had positive but statistically insignificant effects. The interaction term (Product of self-efficacy and gender) had positive $(\beta=0.041)$ and statistically significant relationship with the ethical behavior. Therefore, 
results indicate that gender has moderating effects in the defied context.

\section{Discussion}

This research article has interpreted the effects of self-efficacy and gender on the ethical behavior of sales force (in the eastern culture) in the telecommunication context of Pakistan. The study has also examined the moderating role of gender among the defined context. A technique of selfadministered questionnaire was applied to collect data from the sales representatives in different regions of Khyber Pakhtunkhwa, Pakistan. After data collection, correlation statistic and step wise regression were used to analyze results. The results have indicated that self-efficacy has positive and statistically significant relationship with the ethical behavior of the sales force and gender has moderating effects on this relationship. The finding of this study has important implications for the policy makers, marketing practices, and contributed to relevant knowledge area that self-efficacy can be used to create a good impression on the targeted customers. From the results, it has assumed that continues self-enhancement, high level of self-efficacy and selfconfidence have the advantage to achieve the marketing objectives in less educated and less developed areas of Pakistan. It has also noted that gender is an important factor to be considered in marketing strategies to precisely implement the business operations in less educated areas.

The managerial implication was to examine whether self-efficacy has any linkage with the ethical behavior of sales force in Pakistani context, specifically in telecommunication setup. However, the results have confirmed that self-efficacy can be utilized to affect the ethical behavior of sales force. Further, results have shown that gender has moderating effects on the relationship of defined independent and dependent variables. Ren and Chadee (2017) have examined the relationship of ethical leadership, self-efficacy, and job satisfaction along with the moderating role of guanxi and noted that self-efficacy positively mediates the relationship between ethical leadership and job satisfaction. This study is inline in the sense of self-efficacy. Likewise, this study is in line in the sense of self-efficacy and ethical behavior. This study is in line with (Saadellaoui \& Gharbi, 2012) where a relationship of self-efficacy with the perceived ethicality of fear appeals in anti-tobacco advertising was assessed. It was noted that self-efficacy has a positive influence on the perceptions of the ethical nature of an advertisement. It was also noted that self-efficacy has a positive and significant effect on the intention to quit smoking. Likewise Boswell, Zimmerman and Swider (2012) also noted that self-efficacy has a positive impact on the intensity of job searching behavior, the number of job offers and pre-entry fit perceptions in a working environment. This study is in line in the sense of self-efficacy. Likewise, Hyman and Tansey (1990) noted that unethical advertisement has a negative influence on short and long term attachment of customers with organizations. This study is same in the sense of ethics.

\section{Conclusion}

The study has examined the role of self-efficacy in the ethical behavior of the sales force (in the eastern culture) in the telecommunication setup of Pakistan. The study has also examined the moderating role of gender among the defined constructs. The study has used quantitative method to collect data using self-administered questionnaire from the sales representatives of the telecom sector in Khyber Pakhtunkhwa, Pakistan. The study has used a stepwise regression for data analysis. The results indicated that self-efficacy has positive and statistically significant relationship with the ethical behavior of the sales force, while gender has moderating affects on this relationship. Therefore, the results of stepwise regression have rejected the second hypothesis of the study and accepted the remaining two hypotheses. Moreover, self-efficacy has positive correlation with the ethical behavior in describing context. However, it is important to get know that this study has collected data only from a small region and in telecom sector at Khyber Pakhtunkhwa, Pakistan. Therefore, practitioners and readers should know about the boundary line to generalize the results. To get more exploration in the relevant knowledge area, this study recommends assessing the moderating role of education and culture in services as well as 
manufacturing sectors in Pakistan and in other parts of the world.

\section{References}

Ate.H.(2012). Ethical Perceptions of Public-Sector Employees and Citizens and their Impact upon Attitudes against Unethical Behavior. Turkish Studies, 13(1): 27-44.

Bandura, A., \& Locke, E. A.(2003). Negative self-efficacy and goal effects visited. Journal of Applied Psychology, 88: 87-99.

Boswell, W.R., Zimmerman, R.D., \&Swider, B. W. (2012). Employee job search toward an understanding of search context and search objectives. Journal of Management, 38: 129163.

Chemers. M. M., Watson, C. B., \&May, S. T. (2000). Dispositional affect and leadership effectiveness: A comparison of self-esteem, optimism, and efficacy. Personality and Social Psychology Bulletin, 26(3): 267-277.

Dauenbeimer, D. G., Stablberg, D .,Spreemann, S., \&Sedikides, C. (2002). Self-enhancement, self-verification, or self-assessment: the intricate role of trait modifiability in the selfevaluation process. Revue internationale de psychologiesociale, 15 (3-4): 89-112.

Dinther, M., Dochy, F., \&Segers, M. (2011). Factors affecting students' self-efficacy in higher education. Educational Research Review, 6(2): 95-108.

Fu. W. (2013). The Impact of Emotional Intelligence, Organizational Commitment, and Job Satisfaction on Ethical Behavior of Chinese Employees. In, J Bus Ethics. Springer Science, Business Media Dordrecht.

Gangwani, S. (2012). The impact of Demographicvariables on ethical behavior of employees at their work place, Bauddhik 3: 44-54.

Gefen, D., \& Straub, D. (1997). Gender differences in perception and adoption of email: An extension to the technology acceptance model.MISQuarterly, 21: 389-400.

Grob. T. H.(2015). What is Confidence- A Scientific Definition. Retrived from:http://www.comfortzonecrusher.com/what-is-confidence-a-scientific-definition/, 10/11/16.

Hyman, M. R. \&Tansey, R.(1990). TheEthics of Psychoactive Ads.Journal of Business Ethics, 9(2): 105-114.

Jack. W. (2013). The keys to managerconfidence, Red book solution.

Lam, S. S., Chen, X.-P., \&Schaubroeck, J.(2002). Participative decision making and employee performance in different cultures: The moderating effects of allocentrism / idiocentrism and efficacy. Academy of Management Journal,45(5): 905-914.

Locke, K. D.(2003). Status and solidarity in social comparison: Agentic and communal values and vertical and horizontal directions. Journal of Personality and Social Psychology, 84:619-631.

Luthans, F., and Youssef, C. M. (2007). Emerging positive organizational behavior. Journal of Management, 33(3): 321-349.

Luthans, F., Zhu, W., \&Avolio, B. J, (2006). The impact of efficacy on work attitudes across Cultures, Journal of World Business,41(2): 121-132.

MacIntyre, P. D., Clément, R.,Dörnyei, Z., \& Noels, K.A. (1998). Conceptualising willingness to communicate in a L2: A situational model of L2 confidence and affiliation. Modern Language Journal, 82: 545-562.

Maddux, J. E.(1995). Self-efficacy Theory, Springer.

Nysveen, H., Pedersen, P. E., \&Thorbjornsen, H. (2005). Explaining intention to use mobile Chat services: Moderating effects of gender.Journal of Consumer Marketing, 22(5): 247-256.

Ono, H., \&Zavodny, M. (2002). Gender and the internet.SSE/EFI Working Paper Series in Economics and Finance,495. Stockholm, Sweden: Stockholm School of Economics.

Pelletier.K.L.,\&Bligh.M.C.(2006).Rebounding from Corruption: Perceptions of Ethics Program Effectiveness in a Public SectorOrganization, Journal of Business Ethics, 10551-66.

Ramayah, T., \& Osman, M. (2005).Complementing classroom teaching with an internet course 
website: Does gender and race matter. Proceedings of the 5th SouthEast Asia Association for Institutional Research Conference.Westin Resort Nusa Dua, Bali, Indonesia, 14-16 September.

Ren,S., \&Chadee, D. (2017). Ethical leadership, self-efficacy and job satisfaction in China: the moderating role of guanxi, Personnel Review, 46(2): 371 - 388.

Saadellaoui.I.,\&Gharbi.J. (2012). Effect ofthe Self-Efficacy on the Perceived Ethicality of Fear Appeals in Anti-Tobacco Advertising, Journal of Marketing Research \& Case Studies, 740962, 11.

Sedikides, C., \&Strube, M. J.(1995). The multiply motivated self. Personality and Social Psychology Bulletin, 21:1330-1335.

Sedikides, C., \& Gregg, A. P.(2008). Self-Enhancement: Food for Thought, Perspectives on Psychological Science, 3(2): 102-116.

Sedikides, C., \&Strube, M. (1997). Self-Evaluation: To Thine Own Self Be Good, To Thine Own Self Be Sure, To Thine Own Self Be True, and To Thine Own Self be Better". Advances in Experimental Social Psychology, 29: 209-269.

Shacklock. A., Manning.M., \& Hort. L. (2013). Self-efficacy as an intervening variable between ethical work climate and decision making, e-Journal of Social \&Behavioural Research in Business. 4(2): 1-13.

Stajkovic, A. D., \&Luthans, F. (1998). Selfefficacy and work-related performance: A metaanalysis. Psychological Bulletin, 124(2): 240-261.

Stajkovic, A., \&Luthans, F.(1998). Social cognitive theory and self-efficacy: Going beyond traditional motivational and behavioural approaches. Organizational Dynamics, 26(4): 6274.

Sukserm,t.,\&Takahashi,Y.(2012). Self-efficacy as a mediator of the relationships between learning and ethical behavior from human resource development in corporate social responsibility activity, Asia-Pacific Journal of Business Administration, 4(1): 8 - 22.

Tierney, P., \& Farmer, S. M.(2002).Creative self-efficacy: Potential antecedents and relationship to creative performance. Academy of Management Journal,45: 1137-1148.

Venkatesh, V., \& Morris, M.G. (2000). Why don't men stop to ask for directions? Gender, social influence, and their role in technology acceptance and usage behavior.MISQuarterly, 24(1): 115-139.

Yun.S.,Takeuchi. R., \& Liu. W. (2007).Employee Self-Enhancement Motives and Job Performance Behaviors: Investigating the Moderating Effects of Employee Role Ambiguity and Managerial Perceptions of Employee Commitment. Journal of Applied Psychology, 92(3): 745-756. 